\title{
EDUCAÇÃO DE BEBÊS E CRIANÇAS BEM PEQUENAS NA EDUCAÇÃO INFANTIL: DIÁLOGOS COM A PRODUÇÃO CIENTÍFICA (2013 - 2017)
}

\author{
EDUCATION OF BABY AND VERY SMALL CHILDREN IN \\ CHILDHOOD EDUCATION: DIALOGUES WITH SCIENTIFIC \\ PRODUCTION $(2013$ - 2017)
}

Raiza Fernandes Bessa de Oliveira ${ }^{1}$ Maévi Anabel Nono ${ }^{2}$

\section{RESUMO}

Este artigo trata-se de um recorte de uma pesquisa desenvolvida em nível de mestrado acadêmico, que buscou-se descrever, discutir e analisar saberes e fazeres de uma professora de bebês na Educação Infantil. Assim, indo ao encontro do movimento historicamente recente de reconstrução do perfil dessa etapa educacional, busca-se investir na reflexão e construção de conhecimento sobre a educação da Primeiríssima Infância, enquanto primeiro e primordial espaço de formação humana. Neste sentido, este estudo, que se caracteriza como bibliográfico, se propôs a realizar um levantamento da produção científica recente em Educação Infantil, mais especificamente o segmento creche (0 a 3 anos), estabelecendo diálogos sobre os indicativos dessa produção, contribuindo, assim, para a reflexão e construção de produção científica e teórica sobre esse contexto tão essencial e complexo. Por meio da pesquisa, foi possível inferir que houve aumento significativo nas pesquisas na área, o que tem permitido a construção de novos conhecimentos sobre a educação da Primeiríssima Infância, bem como possibilitado o debate de questões específicas e desafios desse contexto. Finalmente, defende-se a relevância de pesquisas que tragam à tona as diferentes questões e temáticas da Educação Infantil para as crianças de até 3 anos, uma vez que há, ainda, muito a ser feito, pesquisado, construído e aprendido, tanto por profissionais da área como por pesquisadores que têm a educação de bebê e crianças bem pequenas como foco.

Palavras-chave: 0 a 3 anos. Creche. Educação Infantil.

\section{ABSTRACT}

This article is an excerpt from a research developed at the academic master's level, which sought to describe, discuss and analyze the knowledge and practices of a baby teacher in Early Childhood Education. Thus, meeting the historically recent movement to reconstruct the profile of this educational stage, we seek to invest in the reflection and construction of knowledge about early childhood education, as the first and primary space for human formation. In this sense, this study, which is characterized as bibliographic, proposed to carry out a survey of recent scientific production in Early Childhood Education, more specifically the daycare segment ( 0 to 3 years old),

\footnotetext{
${ }^{1}$ Doutoranda em Educação. Universidade Federal de São Carlos (UFSCar). Mestre em Ensino e Processos Formativos. Universidade Estadual Paulista (Unesp), Instituto de Biociências, Letras e Ciências Exatas, São José do Rio Preto. E-mail: raizafbessa@gmail.com. Orcid: https://orcid.org/0000-0002-2422-4821.

2 Doutora em Educação. Universidade Estadual Paulista (Unesp), Instituto de Biociências, Letras e Ciências Exatas, São José do Rio Preto. E-mail: maevi.nono@unesp.br. Orcid: https://orcid.org/0000-0002-6015-1105.
} 
establishing dialogues about the indications of this production, thus contributing to for the reflection and construction of scientific and theoretical production on this very essential and complex context. Through the research, it was possible to infer that there was a significant increase in research in the area, which has allowed the construction of new knowledge about early childhood education, as well as making it possible to debate specific issues and challenges in this context. Finally, it defends the relevance of researches that bring up the different issues and themes of Early Childhood Education for children up to 3 years old, since there is still much to be done, researched, built and learned, both by professionals the area as well as by researchers who focus on the education of babies and very young children.

Keywords: 0 to 3 years. Day Care. Early Childhood Education.

\section{INTRODUÇÃO}

Este artigo trata-se de um recorte de uma pesquisa, desenvolvida em nível de mestrado acadêmico, e busca-se levantar discussões acerca da educação e cuidado de bebês e crianças bem pequenas ${ }^{1}$ na Educação Infantil. Na referida pesquisa, buscou-se descrever, discutir e analisar saberes e fazeres docentes de uma professora que atua com essa faixa etária em um agrupamento de Berçário II (crianças de 1 a 2 anos de idade), em uma instituição de Educação Infantil pública de um município do noroeste paulista, evidenciando os diferentes aspectos que compõem e influenciam este cenário ainda repleto de incertezas e obstáculos.

Neste recorte, será dada especial atenção ao levantamento realizado sobre as pesquisas que buscam refletir sobre o contexto do atendimento às crianças de 0 a 5 anos na Educação Infantil, mais especificamente, que focalizem ou considerem o segmento creche ( 0 a 3 anos), trazendo à tona as especificidades desta etapa educacional, desta docência, dos bebês e das crianças bem pequenas em contextos de educação formal e coletiva.

Assim, compartilha-se da esperança de que a Educação Infantil, enquanto primeira e importante etapa da Educação Básica brasileira (BRASIL, 1996), possa se constituir com base em conceitos diferenciados dos demais níveis educacionais, por meio de práticas pautadas na indissociabilidade entre cuidado e educação, tendo como eixos norteadores do currículo as interações e a brincadeira (BRASIL, 2010), tendo em vista esta especificidade, evidenciada na escola, na infância e na criança ainda tão pequena e que, necessariamente, carece de ser traduzida em práticas educacionais que a considerem.

Destarte, com este estudo, propõe-se investir na construção de conhecimentos a respeito da educação dos bebês e crianças bem pequenas e das variadas questões que compõem este cenário, e que buscam assumi-lo como espaço importante de formação humana, por meio de práticas qualificadas de cuidado e educação.

\footnotetext{
${ }^{1}$ Nomenclatura adotada pelo documento Base Nacional Comum Curricular (BRASIL, 2018), que compreende bebês como crianças de 0 a 18 meses de idade e crianças bem pequenas como crianças entre 19 meses e 3 anos e 11 meses de idade.
} 
Apesar do aparente consenso em relação à importância da educação da Primeiríssima Infância $^{2}$ e, consequentemente dos estudos e pesquisas que a tenham como foco, este ainda parece ser um desafio a ser enfrentado, tendo em vista a carência de trabalhos que se dedicam a esta investigação. Autores e professores revelam a urgência da ruptura com invisibilidade (GOBATTO; BARBOSA, 2017) dos bebês e suas professoras.

Desse modo, considerando que ainda são poucos os estudos que tratam especificamente das práticas e propostas pedagógicas para os bebês e as crianças bem pequenas e tendo em vista a construção de uma pedagogia específica e singular para este segmento, este estudo se propôs a realizar um levantamento da produção científica recente, estabelecendo diálogos sobre os indicativos dessa produção, contribuindo, assim, para a reflexão e construção de produção científica e teórica sobre esse contexto tão essencial e complexo.

\section{O lugar da creche nas pesquisas sobre a Educação Infantil}

Outros levantamentos sobre pesquisas em Educação Infantil e creche têm sido realizados, a exemplo, o trabalho intitulado "A educação dos bebês e crianças bem pequenas no contexto da educação infantil: indicativos da produção científica recente", apresentado na Reunião Científica Regional da Associação Nacional de Pós-Graduação e Pesquisa em Educação (ANPEd), da autora Fernanda Gonçalves (2016), no qual foi realizado um mapeamento da produção científica nacional registrada no banco de teses e dissertações da Coordenação de Aperfeiçoamento de Pessoal de Nível Superior (CAPES), entre os anos de 2008 a 2011, com foco nas questões que abordavam o cotidiano educativo e a prática pedagógica com bebês no contexto da creche.

O estudo evidenciou aumento relevante na produção científica sobre o tema, o que sugere maior atenção em relação ao atendimento das crianças de 0 a 3 anos na Educação Infantil. Apesar disso, foram encontradas apenas 13 dissertações que se enquadravam dentre as categorias selecionadas para pesquisa (estudos sobre a especificidade docente; estudos sobre as práticas pedagógicas; estudos sobre o desenvolvimento infantil; estudos sobre a função social da creche e relação com as famílias).

Já na pesquisa "Percursos e tendências da produção científica sobre crianças de 0 a 3 anos na ANPEd" (BUSS-SIMÃO; ROCHA; GONÇALVES, 2015) foi realizado um levantamento das pesquisas apresentadas no Grupo de Trabalho 7 (GT7 - Educação de crianças de 0 a 6 anos) da Associação Nacional de Pós-Graduação e Pesquisa em Educação

\footnotetext{
${ }^{2}$ Nomenclatura adotada pela Fundação Maria Cecília Souto Vidigal (PELIZON, 2014), que compreende a Primeiríssima Infância como a fase do nascimento aos 3 anos de idade.
} 
(ANPEd), tendo como objetivo identificar aqueles relacionados à educação das crianças de 0 a 3 anos. O estudo evidenciou que dos 175 trabalhos apresentados entre os anos de 2003 e 2013, somente 23 deles tinham a Primeiríssima Infância como foco, o que representa $13 \%$ da produção científica do Grupo.

Apesar disso, as autoras indicam um aumento em relação às reuniões anteriores, apontando que o crescimento dos trabalhos se deve à preocupação em evitar a cisão entre creche e pré-escola, sob o risco de abrir possibilidade de alternativas de atendimento nãoformais, em espaços domésticos ou não, inadequados aos critérios educacionais, com pessoas sem formação e qualificação.

Outro ponto destacado neste estudo foi o crescimento das pesquisas em Educação Infantil que tomam como referencial a Sociologia da Infância, buscando uma nova concepção de criança, assumindo-a como ator social, ativo nas relações sociais, que produzem e reproduzem cultura. A pesquisa evidenciou que, até o ano de 2008, os estudos versavam sobre questões gerais da educação abrangendo a faixa etária de 0 a 6 anos, não sendo frequente o uso de termos como "0 a 3" ou "bebês". É a partir de 2008 que o termo "bebê" surge como grande tendência nas pesquisas sobre crianças dessa faixa etária e observa-se uma disposição em delimitar a faixa etária entre 0 e 3 anos, superando a tendência em pesquisar questões gerais sobre a Educação Infantil, que raramente dão conta das especificidades dos bebês e crianças bem penas (BUSS-SIMÃO; ROCHA; GONÇALVES, 2015).

Fato este que indica a preocupação com a educação de bebês e crianças bem pequenas e o reconhecimento deste segmento como uma dimensão específica da Pedagogia, do saber docente e do conhecimento científico, sendo uma tendência bastante recente do campo educacional e de ensino brasileiro.

A educação infantil, como área de estudos da Pedagogia, tem se preocupado, desde o século XIX, com a educação das crianças bem pequenas. Porém, durante muitos anos, os estudos e propostas educacionais foram pensados, quase que exclusivamente, para as crianças entre quatro e seis anos. As propostas educacionais focadas em crianças de dois e três anos eram profundamente questionadas tendo em vista que os discursos dominantes afirmavam que os cuidados maternos seriam o modo adequado de educar os bebês e as crianças bem pequenas. [...] Nos últimos anos a demanda pelo atendimento educacional de bebês em creches e pré-escolas vem se ampliando. Grande parte do preconceito com relação a essas instituições está sendo superado, pois os estudos vêm demonstrando o quanto essa experiência educacional, quando realizada em estabelecimentos adequados, traz benefícios para as crianças e contribui com a educação realizada pelas escolas e pelas famílias (BRASIL, 2009, p. 28-29).

Estas pesquisas discutem a produção científica educacional, chamando a atenção para o lugar ocupado pelas temáticas que dizem respeito ao atendimento educacional das crianças de até 3 anos. Embora ambas demonstrem aumento significativo dessa produção, muito ainda deve ser estudado e discutido de modo que os direitos educacionais de bebês e crianças bem 
pequenas sejam amplamente garantidos e, não obstante, de modo que seja possível a construção de uma identidade e valorização docente para as professoras ${ }^{3}$ que atuam com essa faixa etária, bem como a valorização das próprias creches e escolas de Educação Infantil, enquanto espaços qualificados de cuidado e educação.

\section{A creche na produção científica recente (2013-2017)}

Buscando dar continuidade e contribuir com as discussões que inferem sobre o lugar dos bebês e crianças bem pequenas nas discussões e pesquisas educacionais, esta pesquisa apresenta-se como bibliográfica (GIL, 2008), ao passo em que se analisa materiais já elaborados e divulgados a respeito do campo de estudo. Assim, realizou-se um levantamento de trabalhos no Catálogo de Teses e Dissertações da CAPES ${ }^{4}$, publicados entre os anos de 2013 a 2017, compreendendo que a produção científica advinda das teses e dissertações são fontes “[...] muito importantes para a pesquisa, pois muitas delas são constituídas por relatórios de investigações científicas originais ou acuradas revisões bibliográficas" (GIL, 2008, p. 64).

Para tal, utilizou-se o termo de busca "creche", tendo sido consideradas as dissertações de mestrado e teses de doutorado da área de conhecimento "Educação", como critério de seleção. Com estes filtros, foram localizados 228 trabalhos, publicados nos anos de 2013, 2014, 2015, 2016 e 2017, o que representa um número significativo de pesquisas. Destas, 15 foram desconsideradas, uma vez que, ou não tratavam do contexto da creche e da Educação Infantil, ou tinham como foco as crianças a partir dos 4 anos de idade, não sendo os bebês e as crianças bem pequenas considerados no estudo.

Das 213 restantes - 171 dissertações de mestrado e 42 teses de doutorado -, estas poderiam ser organizadas e categorizadas de diferentes formas. Buscando delimitar e discutir em linhas gerais as tendências da produção científica na Educação Infantil, que tenha como foco o atendimento aos bebês e crianças bem pequenas, as pesquisas foram agrupadas de acordo com a proximidade entre temas e focos, que serão a seguir melhor detalhados.

Por meio da leitura de títulos, resumo e trechos dos documentos originais das teses e dissertações, para maior aprofundamento e entendimento das discussões propostas pelas diferentes pesquisas, optou-se pela organização dos trabalhos encontrados em grandes categorias ou temas (LÜDKE; ANDRÉ, 1986), de acordo com a proximidade dos focos de estudo de cada uma, como segue: currículo, planejamento pedagógico, docência, saberes e

\footnotetext{
${ }^{3}$ De acordo com o Censo Escolar de 2019 (INEP, 2019), 97,4\% das professoras que atuam em creches e 94,3\% das que atuam no segmento pré-escola são do sexo feminino, por isso a opção do uso do termo "professoras".

${ }^{4}$ Acesso via: https://catalogodeteses.capes.gov.br/catalogo-teses/\#!/
} 
fazeres/práticas docentes; políticas públicas, perspectiva histórica e judicialização de vagas; formação inicial, contínua e continuada; foco no bebê/criança bem pequena em contexto de creche; relação com as famílias/visão das famílias sobre a creche; pesquisas documentais e bibliográficas; gestão e/ou coordenação pedagógica; Educação Especial; questões de raça, etnia e gênero; avaliação e autoavaliação; foco em auxiliares e/ou outros profissionais da equipe escolar; espaços físicos, ambiente e infraestrutura das instituições; e outros temas.

Em uma organização quantitativa - ou seja, dos temas com maior quantidade de pesquisas localizadas -, inicia-se pelos 53 trabalhos que versam sobre currículo, planejamento pedagógico, docência, saberes e fazeres/práticas docentes em contexto de creche, tratados com focos mais gerais do cotidiano da Educação infantil, como por exemplo as pesquisas: "Creche: desafios e possibilidades uma proposta curricular para além do Educar e Cuidar" (ANDRÉ, 2016), “A educação da criança de 0 a 3 anos - um olhar para a prática docente" (DELMONDES, 2015) e "Viajando pela educação da Primeiríssima Infância: sentidos e significados dos saberes e fazeres na/da creche atribuídos por seus profissionais" (RODRIGUES, 2016).

Além disso, outras pesquisas objetivaram discutir saberes e práticas sobre aspectos mais específicos, como artes, desenvolvimento da linguagem oral e dimensão corporal, por exemplo: "Construindo Campos de Experiências: Creche, Arte contemporânea e a poética das crianças de 0 a 3 anos" (NALINI, 2015), “Aprendizagem e desenvolvimento da linguagem oral no contexto da educação infantil” (COSTA, 2014) e “A dimensão corporal na relação educativa com bebês: na perspectiva das professoras" (DEMETRIO, 2016).

Ainda nessa categoria, outros três trabalhos tiveram como foco de discussão o perfil e a identidade docente desses profissionais. Destaca-se, também, quantidade expressiva de investigações de campo em creches e escolas de Educação Infantil, por meio de observações e entrevistas com professoras, muitas delas na perspectiva das narrativas. Cabe ressaltar que alguns dos estudos consideraram em suas coletas de dados não apenas as docentes, mas outras profissionais como estagiárias e auxiliares de sala.

Outro tema em grande evidência, somando 46 pesquisas, diz respeito àquelas que com foco nas políticas públicas para a Educação Infantil, acesso a vagas, direito a Educação Infantil, além de pesquisas que partem da perspectiva histórica para discutir o atendimento educacional de bebês e crianças pequenas, são exemplos: "Gasto aluno em creches diretas: estudo de caso em três municípios paulistas" (BORIO, 2015), "Direito à Educação ou Direito à Creche: $\mathrm{O}$ que Fundamenta o Atendimento à Criança de Zero a Três Anos na Região da AMUNESC?" (TRENTINI, 2016) e "Mulheres cuidadoras, mulheres professoras: história, memória e formação profissional na creche área de saúde da Unicamp" (OLIVEIRA, 2014). 
Nessa categoria, outros três trabalhos tinham como foco específico, ainda, a judicialização do acesso a vagas em creches (MENDES, 2017; POLONI, 2017; TAPAROSKY, 2017).

As discussões a respeito da formação inicial, formação contínua e continuada, necessidades formativas e profissionalização foram foco de 21 pesquisas, abordando diferentes perspectivas e propostas de formação continuada para os professores de bebês e crianças bem pequenas, bem como algumas que discutem a formação inicial desses profissionais, como, por exemplo: "Necessidades formativas de professores de crianças de zero a três anos de idade" (CORDÃO, 2013), "Formação em contexto na educação infantil: uma parceria em busca da melhoria da qualidade de uma creche municipal de Fortaleza" (LIMA, 2013) e "Encontros dos rios: Um estudo comparado da formação de professores de educação infantil em dois cursos de Pedagogia, presencial e a distância, da UNIRIO" (CASTRO, 2015).

Em quantidade também expressiva - 20 trabalhos - foram agrupadas as pesquisas que partem do ponto de vista do bebê ou criança, tendo como objetivo de análise suas ações, interações, brincadeiras, expressões, etc., como é possível observar nas pesquisas "Mas os bebês fazem o quê no berçário, heim?" Documentando ações de comunicação, autonomia e saber-fazer de crianças de 6 a 14 meses em um contexto de vida coletiva" (FOCHI, 2013), "E os bebês na creche... brincam? O brincar dos bebês em interação com as professoras" (CARDOSO, 2016) e "A potência das interações dos bebês em uma creche pública do município de Juiz de Fora" (MACARIO, 2017). Neste bloco de pesquisas, observou-se uma diversidade de abordagens teóricas como a Sociologia da Infância ${ }^{5}$, a Pedagogia da Infância e a Perspectiva Histórico-Cultural, por exemplo.

Não obstante, foi o cerne de 12 trabalhos encontrados a discussão sobre as relações entre a escola e a família, bem como as representações e concepções de famílias das crianças que frequentam creches e pré-escolas, sobre variados temas, fato que pode ser observado nas pesquisas "Família e educadores da infância: um diálogo possível" (ALMEIDA, 2013) e "Educação de 0 a 3 anos: a qualidade na perspectiva das famílias de uma creche conveniada" (MACHADO, 2015).

Outros 10 trabalhos investigaram a Educação Infantil por meio de análise documental em contextos específicos, ou ainda se dedicaram a levantamentos e revisões bibliográficas, semelhantes a este estudo: "A educação de bebês e crianças pequenas no contexto da creche: uma análise da produção científica recente” (GONÇALVES, 2014), “Onde estão as crianças

\footnotetext{
${ }^{5}$ Sociologia da Infância: Campo de Estudo que compreende as crianças como atores sociais plenos, levando em consideração os processos de apropriação, reinvenção e reprodução realizados por elas (DELGADO; MÜLLER, 2005).
} 
da Carochinha? Uma investigação na relação pesquisador/criança na produção de conhecimento de uma creche universitária" (MENDES, 2015) e "Panorama quantitativo e qualitativo das teses sobre creche na área de educação" (SILVA, 2014).

Com oito trabalhos encontrados, a educação de bebês e crianças bem pequenas com necessidades educacionais especiais e a inclusão desse público nas instituições foi o tema de estudo de pesquisas como: "Práticas pedagógicas inclusivas no cotidiano da Educação Infantil: considerações sobre a infância e a criança com deficiência e transtornos globais do desenvolvimento" (OLIVEIRA, 2013) e "Educação Infantil e educação especial: os indicadores de matrículas nos municípios do estado de Mato Grosso do Sul (2011-2013)”."

O papel do gestor e/ou coordenador pedagógico foi ponto principal de sete pesquisas encontradas, discutindo desde os desafios da gestão em creches até o papel do gestor na formação continuada dos professores ou, ainda, a visão dos professores sobre o papel do gestor na unidade escolar. São exemplos: “A formação continuada na perspectiva das coordenadoras pedagógicas de creche do município de Fortaleza" (LEITE, 2013) e "O coordenador pedagógico da educação infantil na perspectiva de seus professores" (SANTOS, 2017).

Com seis pesquisas localizadas, as discussões sobre questões étnico raciais, preconceito e questões de gênero em contexto de creche, também foram foco de trabalhos como: ““'O meu cabelo é assim: Igualzinho o da bruxa, todo armado" Hierarquização e racialização das crianças pequenininhas negras na Educação Infantil” (SANTIAGO, 2014), "Significações de gênero e implicações para o trabalho docente nas creches" (KRAUSE, 2017) e "O branqueamento no cotidiano escolar: práticas pedagógicas nos espaços da creche" (MARTINS, 2017).

A avaliação, tanto no sentido da avaliação dos processos de ensino e aprendizagem das crianças de 0 a 3 anos em ambientes formais e coletivos de cuidado e educação, como dos processos de auto avaliação das próprias instituições infantis, foi o tema de cinco trabalhos encontrados. São exemplos: "Políticas e Práticas de Avaliação na Creche: uma pesquisa na rede pública do Município do Rio de Janeiro" (SOUZA, 2017) e "Autoavaliação institucional participativa: uma experiência em duas creches da Rede Municipal de São Paulo" (NASCIMENTO, 2016).

Considerando a diversidade de fatores e aspectos que influenciam o atendimento aos bebês e crianças bem pequenas, cinco pesquisas tiveram como foco de estudo das estagiárias, auxiliares ou ainda outros profissionais que compõem as equipes escolares na Educação Infantil, como se vê em: "Formação em serviço do pessoal não docente proposta no Projeto Político Pedagógico de creches municipais" (BURGER, 2015) e "Não! A auxiliar não é a 
professora!: o papel das auxiliares da educação infantil no contexto de creche no município de Fortaleza" (PINHEIRO, 2017).

Outro aspecto importante a ser estudado e discutido diz respeito aos espaços físicos, ambientes e infraestrutura das instituições infantis. Este foi o foco de outras cinco pesquisas localizadas. O estudo "Crianças, fotografias e práticas: o que dizem os espaços físicos da Educação Infantil” (RICCI, 2016) é um exemplo.

Apesar da estratégia de agrupar as pesquisas localizadas de acordo com a proximidade e similaridade dos temas de estudo, 15 pesquisas apresentaram focos muito específicos e acabaram não se aproximando das categorias criadas para o detalhamento dos dados, o que resultou na criação de um novo grupo, denominado "outros temas", que reúne pesquisas com temas únicos (ou até duas pesquisas) com tal foco. São exemplos de temas das pesquisas que compõem este grupo: docência masculina na creche, Educação Infantil do campo, educação ambiental, desenhos animados infantis, livros infantis, aspectos de higiene, dentre outros.

Na Tabela 1 estão sistematizados os dados localizados e discutidos por meio do levantamento realizado no Catálogo de Teses e Dissertações da Capes, separados por categoria e por ano de publicação:

Tabela 1. Pesquisas do Catálogo de Teses e Dissertações da Capes.

\begin{tabular}{|l|c|c|c|c|c|c|}
\hline \multicolumn{1}{|c|}{ Temas } & $\mathbf{2 0 1 3}$ & $\mathbf{2 0 1 4}$ & $\mathbf{2 0 1 5}$ & $\mathbf{2 0 1 6}$ & $\mathbf{2 0 1 7}$ & Total \\
\hline $\begin{array}{l}\text { Currículo, planejamento pedagógico, docência, } \\
\text { saberes e fazeres/práticas docentes }\end{array}$ & 6 & 14 & 10 & 12 & 11 & 53 \\
\hline $\begin{array}{l}\text { Políticas públicas e perspectiva histórica e } \\
\text { judicialização de vagas }\end{array}$ & 4 & 8 & 7 & 15 & 12 & 46 \\
\hline Formação inicial, contínua e continuada & 6 & 3 & 4 & 3 & 5 & 21 \\
\hline $\begin{array}{l}\text { Foco no bebê/criança bem pequena em contexto } \\
\text { de creche }\end{array}$ & 5 & 3 & 5 & 3 & 4 & 20 \\
\hline $\begin{array}{l}\text { Relação com as famílias/visão das famílias sobre } \\
\text { a creche }\end{array}$ & 2 & 3 & 2 & 1 & 4 & 12 \\
\hline Pesquisas documentais e bibliográficas & 2 & 3 & 1 & 3 & 1 & 10 \\
\hline Gestão e/ou coordenação pedagógica & 1 & 2 & 0 & 2 & 2 & 7 \\
\hline Educação Especial & 2 & 0 & 4 & 2 & 0 & 8 \\
\hline Questões de raça, etnia e gênero & 0 & 1 & 3 & 0 & 2 & 6 \\
\hline Avaliação e auto avaliação & 1 & 0 & 0 & 2 & 2 & 5 \\
\hline $\begin{array}{l}\text { Foco em auxiliares e outros profissionais da } \\
\text { equipe escolar }\end{array}$ & 0 & 2 & 2 & 0 & 1 & 5 \\
\hline $\begin{array}{l}\text { Espaços físicos, ambiente e infraestrutura das } \\
\text { instituições }\end{array}$ & 2 & 0 & 1 & 2 & 0 & 5 \\
\hline Outros temas & 2 & 3 & 2 & 5 & 3 & 15 \\
\hline & 33 & 42 & 41 & 50 & 47 & $\mathbf{2 1 3}$ \\
\hline
\end{tabular}

Fonte: Elaborado pelas autoras.

Buscando ampliar ainda mais o entendimento sobre a produção científica no âmbito da creche, levantamento semelhante - com o uso da mesma palavra-chave (creche), mesmo 
recorte temporal (2013-2017) e área (Educação) - foi realizado na Biblioteca Digital de Teses e Dissertações - BDTD ${ }^{6}$, do Instituto Brasileiro de Informação em Ciência e Tecnologia (IBICT).

Como resultado dessa busca, foram localizadas mais 80 pesquisas, sendo que seis foram excluídas por não considerarem o contexto da creche e outras 43 apareceram como duplicadas em relação à primeira busca.

Desse modo, foi possível organizar mais 31 pesquisas, das quais: 10 tiveram como foco de estudo o currículo, planejamento pedagógico, docência, saberes e fazeres/práticas docentes; seis tinham como centro das discussões a gestão, o papel e os desafios da coordenação pedagógica na Educação Infantil; três pesquisas tiveram como foco principal os bebês e as crianças bem pequenas, seu desenvolvimento e aprendizagem em contexto de creche; três discutiram questões de formação inicial, contínua ou continuada de professores de creche/Educação Infantil; três trabalhos discutiram políticas públicas educacionais para a educação infantil e a creche; uma pesquisa objetivou discutir a participação e atuação de outros funcionários da equipe escolar da Educação Infantil; uma pesquisa trouxe a questão da avaliação; uma pesquisa focalizou as questões de educação de bebês e crianças com necessidades educacionais especiais; uma pesquisa discutiu questões de gênero e sexualidade para professores de creche e Educação Infantil; e, finalmente, três trabalhos abordaram outros temas, como a docência masculina na creche e a parceria entre a escola e a comunidade em projetos específicos, por exemplo. A tabela abaixo sistematiza esses dados:

TABELA 2. Pesquisas do Banco Digital de Teses e Dissertações do IBICT.

\begin{tabular}{|c|c|c|c|c|c|c|}
\hline Temas & 2013 & 2014 & 2015 & 2016 & 2017 & Total \\
\hline $\begin{array}{l}\text { Currículo, planejamento pedagógico, docência, } \\
\text { saberes e fazeres/práticas docentes }\end{array}$ & 2 & 0 & 3 & 5 & 0 & 10 \\
\hline Gestão e/ou coordenação pedagógica & 1 & 0 & 2 & 2 & 1 & 6 \\
\hline $\begin{array}{l}\text { Foco no bebê/criança bem pequena em contexto } \\
\text { de creche }\end{array}$ & 1 & 1 & 0 & 0 & 1 & 3 \\
\hline Formação inicial, contínua e continuada & 1 & 0 & 0 & 0 & 2 & 3 \\
\hline $\begin{array}{l}\text { Políticas públicas e perspectiva histórica e } \\
\text { judicialização de vagas }\end{array}$ & 0 & 1 & 0 & 2 & 0 & 3 \\
\hline $\begin{array}{l}\text { Foco em auxiliares e outros profissionais da } \\
\text { equipe escolar }\end{array}$ & 0 & 0 & 1 & 0 & 0 & 1 \\
\hline Avaliação e auto avaliação & 0 & 1 & 0 & 0 & 0 & 1 \\
\hline Educação Especial & 0 & 0 & 0 & 0 & 1 & 1 \\
\hline Questões de raça, etnia e gênero & 0 & 0 & 1 & 0 & 0 & 1 \\
\hline Outros temas & 0 & 0 & 1 & 0 & 1 & 2 \\
\hline Total & 5 & 3 & 8 & 9 & 6 & 31 \\
\hline
\end{tabular}

Fonte: Elaborado pelas autoras.

\footnotetext{
${ }^{6}$ Acesso via: https://bdtd.ibict.br/vufind/
} 
Assim, ao todo, foram localizadas, organizadas e categorizadas 244 pesquisas - sendo 197 dissertações de mestrado e 47 teses de doutorado - quantidade expressiva de trabalhos, o que possibilita ampla discussão sobre diversos aspectos da realidade da Educação Infantil e, especificamente, da educação de bebês e crianças bem pequenas em contexto educacional. A tabela abaixo sistematiza as pesquisas encontradas em ambos os bancos de dados, separadas por ano de publicação.

TABELA 3. Total de pesquisas localizadas (2013-2017).

\begin{tabular}{|c|c|c|c|c|c|c|}
\hline Catálogo & 2013 & 2014 & 2015 & 2016 & 2017 & Total \\
\hline $\begin{array}{l}\text { Banco de Teses e Dissertações da } \\
\text { Capes }\end{array}$ & 33 & 42 & 41 & 50 & 47 & 213 \\
\hline $\begin{array}{l}\text { Banco Digital de Teses e Dissertações } \\
\text { do IBICT }\end{array}$ & 5 & 3 & 8 & 9 & 6 & 31 \\
\hline Total & 38 & 45 & 49 & 59 & 53 & 244 \\
\hline
\end{tabular}

Fonte: Elaborado pelas autoras.

Com este levantamento e o detalhamento das pesquisas encontradas, foi possível observar aumento significativo das pesquisas que têm como foco as práticas e saberes docentes desses profissionais, bem como outras que debatem as políticas públicas para a Educação Infantil e a creche, temas determinantes para a ampliação e qualificação deste atendimento. Não obstante, foi possível evidenciar o interesse em investigar uma variedade de temas e aspectos que atravessam o cuidado e educação de bebês e crianças bem pequenas nas creches e escolas de Educação Infantil, o que contribui potencialmente com a visibilidade desta etapa educacional.

Certamente, já houve avanço neste sentido, entretanto, é preciso insistir na necessidade de estudos e pesquisas sobre a Educação Infantil, especialmente das crianças até os três anos.

Nas últimas décadas, observamos um crescimento das investigações no campo da educação das infâncias, porém as crianças de zero a 3 anos ainda permanecem à margem das pesquisas, e os trabalhos têm se preocupado, com maior veemência, com as crianças de 4 a 6 anos, que fazem parte da educação básica obrigatória (DELGADO; FILHO, 2013, p. 22).

Este levantamento corrobora com este indicativo, pois, ao se comparar quantitativamente os dados obtidos pelas pesquisas anteriormente citadas (BUSS-SIMÃO; ROCHA; GONÇALVES, 2015; GONÇALVES, 2016), infere-se aumento bastante significativo de pesquisas que têm como foco a educação e cuidado de bebês e crianças bem pequenas na Educação Infantil, com amplitude e diversidade de temas e aspectos que compõem esta etapa educacional e que a reafirmam como espaço complexo e determinante de formação humana. 
O aumento no número de trabalhos evidencia o movimento de conscientização e estudo a respeito da importância da educação das crianças de 0 a 3 anos de idade em ambientes formais e coletivos de educação. Assim, concorda-se com Tristão (2004) quando aponta para a

[...] necessidade de estudos que indiquem as especificidades do trabalho com crianças bem pequenas nos contextos institucionais, uma vez que a ação pedagógica nos berçários ainda é um processo em construção. As pesquisas tendo como foco o cuidado e a educação de crianças de até três anos são cruciais na definição de critérios de qualidade para os serviços educacionais prestados a esta faixa etária, bem como na estruturação de diretrizes para a formação das profissionais que lidarão com crianças tão pequenas (p. 8).

Torna-se possível inferir, então, que houve ampliação importante da produção científica na área, o que tem permitido a construção de novos conhecimentos sobre a educação da Primeiríssima Infância, bem como possibilitado o debate de questões específicas e desafios desse contexto. Do mesmo modo, ampliaram-se também os focos de estudo, sendo abordados diferentes temas, questões e especificidades da educação e cuidado de bebês e crianças bem pequenas na creche.

Dessa forma, defende-se a relevância de pesquisas que tragam à tona as diferentes questões da Educação Infantil para as crianças de até 3 anos. Torna-se necessário que novas pesquisas e trabalhos sejam realizados e contribuam no sentido de ampliar a qualidade do atendimento ofertado, e isso só se torna possível por meio de formação adequada dos profissionais, aprimoramento da prática educativa na Educação Infantil, além de políticas públicas educacionais e investimentos na área.

\section{Conclusão}

Apesar do evidente crescimento no número de pesquisas que focalizam a educação e o cuidado de bebês e crianças bem pequenas na Educação Infantil e os variados temas que compõem este cenário, entende-se que ainda há muito a ser feito, discutido, pesquisado, construído e aprendido, tanto por profissionais como por pesquisadores que têm a Primeiríssima Infância como foco.

As vivências e experiências dos primeiros anos de vida constituem-se como determinantes para a formação e desenvolvimento humano de bebês e crianças. Portanto, defende-se a relevância das pesquisas que discutem o atendimento educacional das crianças de 0 a 3 anos, bem como os saberes e práticas de suas professoras.

Conceber de forma singular a educação e o cuidado das crianças dessa faixa etária ainda se mostra um imenso desafio, visto que este é um tema que, apesar do crescimento evidenciado, ainda permanece invisibilizado em diferentes aspectos, e às margens na 
formação inicial docente, nas pesquisas educacionais e nas políticas públicas educacionais brasileiras (GOBATTO; BARBOSA, 2017). Não obstante, os profissionais que atuam com os bebês e as crianças bem pequenas sofrem diariamente com a desvalorização e precarização de seu trabalho, marcas históricas dessa etapa da Educação Básica (DIAMENTE, 2010; OLIVEIRA, 2017; MIORI, 2018).

Faz-se necessário, então, caminhar no sentido da valorização das professoras que atuam com bebês e crianças bem pequenas na Educação Infantil, sendo imprescindível, também, dissertar sobre a qualidade do atendimento a eles oferecido, buscando a construção de uma pedagogia específica, intencional e qualificada, que promova a garantia de seus direitos educacionais e uma escola que os entenda como sujeitos únicos, ativos, criativos e potentes.

Embora a Educação Infantil e a creche tenham alcançado maior visibilidade nas últimas décadas, uma educação da Primeiríssima Infância, de fato, ainda engatinha em relação a sua efetivação nas instituições públicas, nos variados contextos brasileiros.

Considera-se que esta pesquisa vai ao encontro de pesquisadores e profissionais que entendem a educação dos bebês e crianças bem pequenas como primordial para a formação humana e buscam a construção e consolidação de uma pedagogia específica.

Nesse sentido, busca-se possibilitar que elas tenham acesso a uma educação infantil humanizadora e emancipadora, por meio de um ambiente rico e seguro, com práticas educativas de qualidade, pautadas nas interações e na brincadeira, que concebam cuidado e educação como indissociáveis e que promovam aos bebês e crianças bem pequenas experiências, aprendizagens e desenvolvimento, valorizando os modos de ser e agir infantil, respeitando suas singularidades e permitindo que cresçam e construam sua autonomia, identidade e autoestima.

\section{Referências}

ALMEIDA, Flavia Maria Cabral de. Família e educadores da infância: um diálogo possível. Rio de Janeiro. Tese (Doutorado). 176 f. Universidade do Estado do Rio de Janeiro, Rio de Janeiro, 2013.

ANDRÉ, Rita de Cássia Marinho de Oliveira. Creche: desafios e possibilidades uma proposta curricular para além do educar e cuidar. 185 f. Dissertação (Mestrado em Educação: Currículo) - Programa de Estudos Pós-Graduados em Educação: Currículo, Pontifícia Universidade Católica de São Paulo, São Paulo, 2016.

BORIO, João Carlos. Gasto aluno em creches diretas: estudo de caso em três municípios paulistas. Dissertação (Mestrado em Educação). 180 f. Universidade de São Paulo, São Paulo, 2015. 
BRASIL. Ministério da Educação. Diretrizes Curriculares Nacionais para a Educação Infantil. Brasília, 2010.2 DF, Disponível em: <http://portal.mec.gov.br/dmdocuments/diretrizescurriculares_2012.pdf>. Acesso em: 05 nov. 2020.

Ministério da Educação. Práticas cotidianas na educação infantil: bases para reflexão sobre as orientações curriculares: Projeto de cooperação técnica MEC / Universidade Federal do Rio Grande do Sul para construção de orientações curriculares para a educação infantil. Brasília, DF, 2009. Disponível em: <http://portal.mec.gov.br/dmdocuments/relat_seb_praticas_cotidianas.pdf>. Acesso em: 05 nov. 2020.

Ministério da Educação. Secretaria da Educação Básica. Base Nacional Comum Curricular. Brasília, DF, 2018. Disponível em: http://basenacionalcomum.mec.gov.br/>. Acesso em 05 nov. 2020.

. Presidência da República. Casa Civil. Lei $n^{\circ}$ 9.394/96, de 20 de dezembro de 1996. Estabelece as diretrizes e bases da educação nacional. Disponível em: <http://www.planalto.gov.br/ccivil_03/Leis/19394.htm>. Acesso em: 05 nov. 2020.

BURGER, Edneia Regina. Formação em serviço do pessoal não docente proposta no Projeto Político Pedagógico de creches municipais. Dissertação (Mestrado em Educação: Currículo). Pontifícia Universidade Católica De São Paulo, São Paulo, 2015.

BUSS-SIMÃO, Márcia; ROCHA, Eloisa Acires Candal; GONÇALVES, Fernanda. Percursos e tendências da produção científica sobre crianças de 0 a 3 anos na Anped. Revista Brasileira de Estudos Pedagógicos, Brasília, v. 96, n. 242, p. 96-111, 2015. Disponível em: https://www.scielo.br/pdf/rbeped/v96n242/2176-6681-rbeped-96-242-00096.pdf>. Acesso em: 05 nov. 2020.

CASTRO, Leonardo Villela de. Encontro dos rios: um estudo comparado da formação de professores de educação infantil em dois cursos de pedagogia, presencial e a distância, da UNIRIO. Tese (Doutorado). 243 f. Universidade Federal do Rio de Janeiro, Rio de Janeiro, 2015.

COLL, Ana Cristina Coll; MÜLLER, Fernanda. Sociologia da infância: pesquisa com crianças. Educação \& Sociedade, Campinas, v. 26, n. 91, p. 351-360, maio/ago. 2005. Disponível em: <https://www.scielo.br/pdf/es/v26n91/a02v2691〉. Acesso em 05 nov. 2020.

CORDÃO, Taciana Saciloto Real. Necessidades formativas de professores de crianças de zero a três anos de idade. Dissertação (Mestrado). 207 f. Pontifícia Universidade Católica de Campinas, Campinas, 2013.

CARDOSO, Michelle Duarte Rios. E os bebês na creche...brincam? O brincar dos bebês em interação com as professoras. Dissertação (Mestrado). $197 \mathrm{f}$. Universidade Federal de Juiz de Fora, Juiz de Fora, 2016

COSTA, Wanessa Rafaela do Nascimento da. Aprendizagem e desenvolvimento da linguagem oral no contexto da Educação Infantil. Dissertação (Mestrado). $106 \mathrm{f}$. Universidade Federal Do Rio Grande do Norte, Natal, 2014. 
DELGADO, Ana Cristina Coll; FILHO, Altino José Martins. Dossiê "bebês e crianças bem pequenas em contextos coletivos de educação". Pro-Posições, São Paulo, v. 24, n. 3, p. 21-30, set./dez. 2013. Disponível em: https://periodicos.sbu.unicamp.br/ojs/index.php/proposic/article/view/8642514/10035>. Acesso em: 05 nov. 2020.

DELMONDES, Iraildes Sales dos Santos. A educação da criança de 0 a 3 anos - um olhar para a prática docente. Dissertação (Mestrado). 173 f. Universidade Católica Dom Bosco, Campo Grande, 2015.

DEMETRIO, Rubia Vanessa Vicente. A dimensão corporal na relação educativa com bebês: na perspectiva das professoras. Dissertação (Mestrado). 170 f. Universidade Federal de Santa Catarina, Florianópolis, 2016.

DIAMENTE, Juliana. A dimensão subjetiva do trabalho em educação infantil: o impacto da desvalorização nos sentidos constituídos pelos professores. Dissertação (Mestrado em Psicologia). 178 f. Pontifícia Universidade Católica de São Paulo, São Paulo, 2010.

FOCHI, Paulo Sergio. "Mas os bebês fazem o quê no berçário, heim?" Documentando ações de comunicação, autonomia e saber-fazer de crianças de 6 a 14 meses em um contexto de vida coletiva. Dissertação (Mestrado). 171 f. Universidade Federal do Rio Grande do Sul, Porto Alegre, 2013.

GIL, Antonio Carlos. Métodos e técnicas em pesquisa social. São Paulo: Atlas, 2008.

GOBATTO, Carolina; BARBOSA, Maria Carmen Silveira. A (dupla) invisibilidade dos bebês e das crianças bem pequenas na educação infantil: tão perto, tão longe. Revista Humanidades e Inovação, v. 4, n. 1, 2017. Disponível em: $<$ https://revista.unitins.br/index.php/humanidadeseinovacao/article/view/289>. Acesso em: 05 nov. 2020.

GONÇALVES. Fernanda. A educação de bebês e crianças pequenas no contexto da creche: uma análise da produção científica recente. Dissertação (Mestrado). 202 f. Universidade Federal de Santa Catarina, Florianópolis, 2014.

A educação dos bebês e crianças bem pequenas no contexto da educação infantil: indicativos da produção recente. In: REUNIÃO CIENTÍFICA REGIONAL DA ASSOCIAÇÃO NACIONAL DE PÓS-GRADUAÇÃO. Curitiba, 2016. Disponível em: $<$ http://www.anpedsul2016.ufpr.br/portal/wp-content/uploads/2015/11/Eixo-5_FERNANDAGON\%C3\%87ALVES.pdf>. Acesso em: 05 nov. 2020.

INSTITUTO NACIONAL DE ESTUDOS E PESQUISAS EDUCACIONAIS ANÍSIO TEIXEIRA (INEP). Sinopse Estatística da Educação Básica 2019. Brasília: Inep, 2020. Disponível em: <http://portal.inep.gov.br/sinopses-estatísticas-da-educacao-basica>. Acesso em: 05 nov. 2020.

KRAUSE, Cristina da Silva Cavalcante. Significações de gênero e implicações para o trabalho docente nas creches. Dissertação (Mestrado). 286 f. Universidade Federal do Acre, Rio Branco, 2017.

LEITE, Maria Ilnair Martins. A formação continuada na perspectiva das coordenadoras pedagógicas de creche do município de Fortaleza. Dissertação (Mestrado). 105 f. Universidade Federal do Ceará, Fortaleza, 2013. 
LIMA, Antonia Emanuela Oliveira de. Formação em contexto na Educação Infantil: uma parceria em busca da melhoria da qualidade de uma creche municipal de Fortaleza. Tese (Doutorado). 295 f. Universidade Federal do Ceará, Fortaleza, 2013.

LÜDKE, Menga. ANDRÉ, Marli E. D. A. Pesquisa em educação: abordagens qualitativas. São Paulo: EPU, 1986, p. 38-44.

MACÁRIO, Alice De Paiva. A potência das interações dos bebês em uma creche pública do município de Juiz de Fora. Dissertação (Mestrado). 169 f. Universidade Federal de Juiz de Fora, Juiz de Fora, 2017.

MACHADO, Zenaide Souza. Educação de 0 a 3 anos: a qualidade na perspectiva das famílias de uma creche conveniada. Dissertação (Mestrado). $116 \mathrm{f}$. Universidade Federal de Santa Catarina, Florianópolis, 2015.

MARTINS, Telma Cezar Da Silva. O branqueamento no cotidiano escolar: Práticas pedagógicas nos espaços da creche. Tese (Doutorado). 290 f. Universidade Nove de Julho, São Paulo, 2017.

MENDES, Beatriz Fatima. Sempre cabe mais um! A qualidade da educação infantil frente às matrículas via decisões judiciais. Dissertação (Mestrado). 132 f. Pontifícia Universidade Católica de Campinas, Campinas, 2017.

MIORI, André Freitas. A produção acadêmica sobre a função do professor de creche: um tema em debate. Dissertação (Mestrado). 188 f. Pontifícia Universidade Católica de São Paulo, São Paulo, 2018.

NALINI, Denise. Construindo Campos de Experiências: Creche, Arte contemporânea e a poética das crianças de 0 a 3 anos. Tese (Doutorado). 228 f. Universidade de São Paulo, São Paulo, 2015.

NASCIMENTO, Aline Dias. Autoavaliação institucional participativa: uma experiência em duas creches da Rede Municipal de São Paulo. Dissertação (Mestrado). 154 f. Pontifícia Universidade Católica de São Paulo, São Paulo, 2016.

PINHEIRO, Maria Nerice dos Santos. Não! A auxiliar não é a professora!: O papel das auxiliares da educação infantil no contexto de creche no município de Fortaleza. Dissertação (Mestrado). 340 f. Universidade Federal do Ceará, Fortaleza, 2017.

POLONI, Maria José. Creche: do direito à educação à judicialização da vaga. Tese (Doutorado). 208 f. Universidade Nove de Julho, São Paulo, 2017.

OLIVEIRA, Carla de. Mulheres cuidadoras, mulheres professoras: história, memória e formação profissional na creche. Dissertação (Mestrado). $178 \mathrm{f}$. Universidade Estadual de Campinas, Campinas, 2014.

OLIVEIRA, Keila Cristina Belo da Silva. Práticas pedagógicas inclusivas no cotidiano da educação infantil: considerações sobre a infância e a criança com deficiência e transtornos globais do desenvolvimento. Dissertação (Mestrado). 145 f. Universidade Federal do Espírito Santo, Vitória, 2013. 
OLIVEIRA, Tiago Grama de. Docência e educação infantil : condições de trabalho e profissão docente. Dissertação (Mestrado). 173 f., Universidade Federal de Minas Gerais, Belo Horizonte, 2017.

PELIZON, Marina Helena. Formação em educação infantil: zero a três anos. São Paulo: Fundação Maria Cecilia Souto Vidigal, 2014.

RICCI, Aline do Nascimento. Crianças, fotografias e práticas: o que dizem os espaços físicos da educação infantil. Dissertação (Mestrado). 139 f. Universidade Federal do Estado do Rio de Janeiro, Rio de Janeiro, 2016.

RODRIGUES, Silvia Adriana. Viajando pela educação da Primeiríssima Infância: sentidos e significados dos saberes e fazeres na/da creche atribuídos por seus profissionais. Tese (Doutorado). 235 f. Universidade Estadual Paulista Júlio de Mesquita Filho, Presidente Prudente, 2016.

RONDON, Marcelo Messias. Educação Infantil e educação especial: os indicadores de matrículas nos municípios do estado de Mato Grosso do Sul (2011-2013). Dissertação (mestrado). 125 f. Universidade Federal de Mato Grosso do Sul, Corumbá, 2016.

SANTIAGO, Flavio. "O meu cabelo é assim ... Igualzinho o da bruxa, todo armado:" Hierarquização e racialização das crianças pequenininhas negras na Educação Infantil. Dissertação (Mestrado). 127 f. Universidade Estadual de Campinas, Campinas, 2014.

SANTOS, Luizyana Magda Coelho dos. O coordenador pedagógico da Educação Infantil na perspectiva de seus professores. Dissertação (Mestrado). 81 f. Pontifícia Universidade Católica de São Paulo, São Paulo, 2017.

SILVA, Angelica Aparecida Ferreira da. Panorama quantitativo e qualitativo das teses sobre creche na área de educação (2007 a 2011). Dissertação (Mestrado). 133 f. Universidade de Brasília, Brasília, 2014.

SOUZA, Marina Pereira de Castro e. Políticas e Práticas de Avaliação na Creche: uma pesquisa na rede pública do Município do Rio de Janeiro. Tese (Doutorado). 230 f. Pontifícia Universidade Católica do Rio de Janeiro, Rio de Janeiro, 2017.

TAPOROSKY, Barbara Cristina Hanauer. O Controle Judicial Da Qualidade Da Oferta Da Educação Infantil: Um Estudo Das Ações Coletivas Nos Tribunais De Justiça Do Brasil (2005-2016). Dissertação (Mestrado). 203 f. Universidade Federal Do Paraná, Curitiba, 2017.

TRENTINI, Julcimara. Direito à educação ou direito à creche: o que fundamenta o atendimento à criança de zero a três anos na região da AMUNESC?. Dissertação (Mestrado). 142 f. Universidade da Região de Joinville, Joinville, 2016.

TRISTÃO, Fernanda Carolina Dias. Ser professora de bebês: uma profissão marcada pela sutileza. Zero-a-Seis, Florianópolis, v. 6, n. 9, p. 1-14, jan./jun. 2004. Disponível em: <https://periodicos.ufsc.br/index.php/zeroseis/article/view/9360/8612>. Acesso em: 05 nov. 2020 . 
